\title{
As representações sociais de transgênicos nos jornais brasileiros
}

\author{
Juliana Mezzomo Allain \\ Clélia Maria Nascimento-Schulze \\ Brígido Vizeu Camargo \\ Universidade Federal de Santa Catarina
}

\begin{abstract}
Resumo
Em alguns países que haviam passado recentemente por graves crises alimentares, os transgênicos receberam forte resistência da população. Nesses países, a mídia teve uma papel importante na discussão crítica e na veiculação dos argumentos de movimentos ambientais e de consumidores sobre os transgênicos. O objetivo dessa pesquisa foi verificar quais as representações sobre transgênicos divulgadas pela mídia impressa brasileira. Foram coletados todos os artigos publicados sobre esse tema nos jornais A Folha de São Paulo e O Estado de São Paulo, entre 2000 e 2005. Os dados foram analisados com ajuda do programa ALCESTE. Os resultados mostram que a mídia nacional ainda contribui mais para uma legitimação dos riscos do que para a construção de representações sociais que possam ser usadas como armas críticas em relação ao modelo de desenvolvimento do país e suas conseqüências para as gerações futuras.
\end{abstract}

Palavras-chave: representações sociais; mídia; transgênicos

\begin{abstract}
Transgenics social representations in Brazilian newspapers. In some countries that had recently experienced severe food crisis, transgenics received a strong rejection from the population. In such countries, the media had an important role in the critical discussion and in the dissemination of environmental organizations or consumers' arguments about transgenics. The goal of this research was to verify which are the social representations of transgenic displayed by Brazilian media. All articles published on this theme by A Folha de São Paulo and O Estado de São Paulo, from 2000 to 2005, were gathered. Data were analyzed with the aid of the software ALCESTE. Results show that the national media tend to legitimate risk rather than to build social representations that could be used as critical arms towards the country's development models and its consequences on future generations.
\end{abstract}

Keywords: social representations; media; transgenic

A biotecnologia moderna surgiu e, principalmente, se desenvolveu, em uma época em que a ciência e a tecnologia começavam a ser questionadas, e até desacreditadas, quanto à incerteza do conhecimento científico, os limites e falhas do seu controle, os interesses por trás de seu desenvolvimento, e os diferentes tipos de riscos a longo prazo. Suas aplicações levantaram questões sobre os impactos ambientais, para a saúde humana e sociais. Igualmente, suas aplicações tocam em aspectos éticos e morais, chegando a questionar o que significa a vida (ao ultrapassar as barreiras que definem a "essência" do ser vivo) e qual o alcance do poder dos homens que "brincam de ser Deus" (Einsiedel \& Kamara, 2006).

Entretanto, talvez a conseqüência mais importante da sua introdução tenha sido a reflexividade e a organização de certos grupos que levaram a um questionamento do processo decisório sobre o desenvolvimento e a aplicação de novas tecnologias cujos riscos ainda são incertos, demandando uma maior participação pública nesse processo (Guivant, 2005).

Em alguns países, principalmente os europeus, a mídia teve um papel importante na discussão crítica sobre a biotecnologia moderna em geral, e os transgênicos em específico. De fato, muitos teóricos argumentam que a mídia tem um papel fundamental na criação de uma reflexividade (Beck, 1999) e de representações sociais (Jodelet, 2001; Moscovici, 1978) que sirvam como armas críticas para a população. Assim, essa pesquisa teve como objetivo verificar como o tema dos transgênicos é tratado pela mídia brasileira, buscando analisar que representações sociais desse tema são divulgadas para a população brasileira. Julga-se que este seja um tema relevante, considerando a importância dada ao modelo de desenvolvimento agrário para o próprio desenvolvimento do país.

\section{Revisão teórica}

A partir dos meados do século XX, nos países capitalistas centrais, foi crescendo o sentimento de que o desenvolvimento 
científico-tecnológico-econômico não conduzia, linear e automaticamente, ao desenvolvimento do bem-estar social. A degradação ambiental e a vinculação do desenvolvimento científico-tecnológico à guerra, fizeram com que a ciência e tecnologia (C\&T) se tornassem alvo de um olhar mais crítico e um objeto de debate político (Auler \& Bazzo, 2001).

Beck (1999) aponta que a sociedade contemporânea mundial está enfrentando problemas que acabam por questionar os fundamentos da modernidade baseada em crenças como: controle da natureza, abundância e progresso, crescimento e prosperidade, fé na C\&T e confiança nas instituições sociais. Tal questionamento leva a mudanças que fazem surgir novas formas de organização social e política. Nas últimas décadas, vários cientistas sociais vêm analisando essas reconfigurações (Beck, 1999; Beck, Giddens \& Lash, 1997; Giddens, 2002).

Ao sistematizar tais reconfigurações, Beck (1999) faz uma distinção entre primeira e segunda modernidade. Este autor utiliza o termo primeira modernidade para se referir à modernidade baseada no Estado-Nação, na qual as relações sociais, as redes e as comunidades são entendidas num sentido territorial. A sociedade típica da primeira modernidade é a sociedade industrial (ou sociedade de risco residual). A segunda modernidade, também chamada por Beck de modernidade reflexiva (ou sociedade de risco), é a fase de radicalização dos princípios da modernidade (Guivant, 2001), ou seja, “designa um estágio da modernidade em que começam a tomar corpo as ameaças produzidas até então no caminho da sociedade industrial” (Beck, 1997, p. 17). Essas ameaças são produzidas porque o pensamento da sociedade industrial é dominado por certezas como progresso e abstração dos riscos. Desse modo, a segunda modernidade implica uma fase no desenvolvimento da sociedade moderna, na qual os riscos, sejam estes sociais, políticos, econômicos ou mesmo individuais, não podem ser mais controlados pelas instituições de proteção próprias da sociedade industrial. Uma conseqüência disto seria um processo de desmonopolização da ciência e a abertura dos processos decisórios sobre o desenvolvimento científico-tecnológico, incluindo a participação da população nesse assunto.

A questão da segurança alimentar tem sido frequentemente apontada como um exemplo na discussão sobre o limite do controle dos sistemas peritos e de uma área que se tornou politizada na sociedade de risco. As mudanças da alimentação na modernidade e as crises alimentares pelas quais alguns países passaram (como a crise da vaca louca) acirraram os conflitos entre leigos e peritos e levaram à redefinição do conceito e da representação de segurança alimentar. Este também foi o pano de fundo para a chegada dos transgênicos.

Fischler (2000) argumenta que, ao se tornar uma área politizada, a questão da segurança alimentar começou a receber mais investimentos para a pesquisa, incluindo aí as pesquisas feitas pelas ciências humanas e sociais. Começam a surgir inúmeras pesquisas sobre a percepção pública da ciência e da tecnologia, a percepção do risco etc. Outro campo de estudo que recebeu grande atenção no cenário internacional, principalmente em relação aos transgênicos, foi a análise de como esse assunto foi tratado pela mídia (Bauer, 2002; Bonfadelli, Dahinden, \& Leonarz, 2002; Görke \& Ruhrmann, 2003; Gutteling et al,
2002; Parales-Quenza, 2004). Segundo Frewer, Miles e Marsh (2002), o aumento do número de matérias sobre alimentos geneticamente modificados levou a uma amplificação social do risco em relação a esse assunto na Inglaterra. Einsiedel e Kamara (2006) mostraram que movimentos sociais (ambientais, de consumidores e de agricultores) que já possuíam experiência em promover visões alternativas para outras tecnologias (nuclear, pesticidas etc), utilizaram o seu conhecimento do uso da informação para disseminar na mídia mensagens sobre transgênicos que focavam na incerteza da avaliação de risco, a importância de se considerar aspectos éticos, ambientais e sociais nas decisões sobre novas tecnologias, além dos interesses por trás da pesquisa científica.

Nesse campo de estudo, a teoria das representações sociais ocupa um lugar de destaque. Segundo Moscovici (2000), as representações sociais são um conjunto de conceitos, afirmações e explicações que se originam no dia a dia, durante a comunicação e cooperação entre indivíduos e grupos. Nesse sentido, as representações sociais nos ajudam a dominar o nosso ambiente, compreender e explicar os fatos e idéias que preenchem o nosso universo, situar-nos a seu respeito, responder às questões que o mundo nos coloca e saber o que as descobertas da ciência e o devir histórico significam (Jodelet, 1986).

Principalmente, no campo de estudos sobre a percepção pública da C\&T, a teoria das representações sociais tem um papel importante porque se interessa em como um novo conhecimento científico se espalha e é apropriado por diferentes grupos sociais, pertencendo a uma tradição que estuda a popularização da ciência desde os anos 60 (Bauer, 1994). Nesse sentido, a mídia como fonte de informação de diversos atores sociais tem um papel fundamental na edificação das representações sociais.

Em seu estudo sobre as representações sociais da psicanálise, Moscovici (1961) empregou três sistemas de comunicação na análise da divulgação desse tema pela mídia: a difusão, a propagação e a propaganda. Esses sistemas são caracterizados de acordo com a fonte, a lógica e a função das mensagens. A comunicação na propaganda visa incidir sobre o comportamento do receptor, a mensagem é estruturada de forma dicotomizada entre o que é certo e o que é errado e a comunicação contém e exprime os interesses de um grupo específico. Assim, um dos objetivos fundamentais da propaganda é a formação de uma representação social. Já a propagação intervém nas atitudes; a mensagem é estruturada de forma a controlar a ameaça de novos conhecimentos sobre o sistema de crenças de um determinado grupo. Desse modo, essas novidades são sempre interpretadas à luz dos sistemas que devem ser preservados. Por fim, comunicação na modalidade difusão visa a transmissão de assuntos gerais a um grande público. A mensagem não é estruturada como nas duas modalidades anteriores, contendo informações e opiniões que são contraditórias sem uma articulação entre as mesmas. O objetivo é garantir ao grande público o acesso às informações.

Nos últimos anos, os transgênicos começaram a despertar a atenção dos pesquisadores brasileiros. No entanto, grande parte das pesquisas nacionais está limitada à análise do processo de regulamentação dessa tecnologia (Labarrère, 2000; Lazzarini, 2000; Porto, 2005) e dos atores envolvidos nesse processo 
(Guivant, 2001; 2002; 2005). O estudo da percepção pública sobre esse assunto é bastante limitada, contrastando com a literatura internacional.

Um parte das pesquisas sobre transgênicos no Brasil também tem se concentrado na análise da cobertura desse tema pela mídia impressa brasileira (Bueno, 1999; Marcolino \& Franco, 2004; Massarani, Magalhães \& Moreira, 2003). Porém, esses estudos se restringem mais à forma do que ao conteúdo que foi divulgado. Asssim, as análises documentais da cobertura da mídia brasileira sobre esse tema apresentam limitações, uma vez que consideram períodos muito curtos (entre um mês e um ano apenas) e priorizam a forma frente ao conteúdo divulgado. Não é possível saber o que é divulgado para a população e que tipo de reflexão acerca desse assunto é proposta. Igualmente, os curtos períodos de análise não permitem ver como esse assunto foi socialmente construído no país. Assim, essa pesquisa teve como objetivo analisar que representações sociais de transgênicos são divulgadas pela mídia para a população brasileira.

\section{Método}

Trata-se de uma pesquisa documental de caráter descritivo que buscou analisar as diferentes representações sociais sobre transgênicos que circularam na mídia impressa (jornais) brasileira. Foram considerados nesse estudo dois jornais nacionais de grande circulação: A Folha de SP e O Estado de SP.

É essencial estudar as representações sociais "na sua construção, do ponto de vista de sua história e desenvolvimento" (Moscovici \& Marková, 2003, p. 331). Assim, foram considerados todos os artigos publicados no período entre janeiro de 2000 a junho de 2005. Considera-se que este seja um período importante para o estudo da construção e do desenvolvimento das representações sociais de transgênicos no Brasil, uma vez que abrange uma parte importante do processo de regulamentação desse tema, incluindo as diferentes arenas pelos quais ele passou, bem como os diferentes atores que passaram a se envolver nessa questão.

Os artigos foram coletados através dos sites de cada editora. A palavra de busca para os artigos foi transgênicos, de modo que todos os artigos coletados eram relacionados a tal assunto, sendo este o tema principal ou não (reportagens, editoriais, notas, cartas de leitores. etc).

Os dados foram analisados com ajuda do programa ALCESTE (Analyse Lexicale par Contexte d'un Ensemble de Segments de Texte; Reinert, 1998) que permite uma análise lexicográfica do material textual e oferece contextos textuais que são caracterizados pelo seu vocabulário, e também por segmentos de textos que compartilham esse vocabulário. O corpus coletado é dividido em classes de palavras que podem indicar representações sociais ou campos de uma representação de um objeto (Camargo, 2005; Nascimento-Schulze \& Camargo, 2000).

\section{Resultados}

A Tabela 1 mostra o número de artigos publicados sobre transgênicos no período considerado na pesquisa.
Como mostra a Tabela 1, foram publicados 2.869 artigos sobre transgênicos nos seis anos. Nota-se que em 2000 há um número alto de publicação. Esse número diminuiu um pouco em 2001 e bastante em 2002. Em 2003, o número de artigos publicados foi maior do que o total dos dois anos anteriores. Em 2004, esse número diminuiu novamente pela metade e em 2005, o número de artigos publicados sobre transgênicos reduziu consideravelmente. O número de artigos publicados por ano reflete o número de acontecimentos envolvendo os transgênicos. A seguir, mostraremos como esses fatos aparecem no conteúdo divulgado pelos jornais.

Tabela 1

Número de artigos publicados sobre transgênicos por jornal e por ano

\begin{tabular}{lccccccc}
\hline Jornal & 2000 & 2001 & 2002 & 2003 & 2004 & 2005 & Total \\
\hline A Folha de SP & 289 & 229 & 153 & 497 & 257 & $106 *$ & 1540 \\
O Estado de SP & 170 & 193 & 131 & 512 & 250 & 73 & 1329 \\
\hline Total & 468 & 422 & 284 & 1.009 & 507 & 179 & 2.869 \\
\hline *170 no ano inteiro & & & & & &
\end{tabular}

Os dados coletados nos dois jornais foram organizados em um corpus denominado Jornal, no qual cada artigo (considerado como uma unidade de contexto inicial - UCI) era antecedido por uma linha de comando que continha três variáveis: artigo (n =2.862), ano (2000, 2001, 2002, 2003, 2004 e 2005), e mídia (A Folha de SP e O Estado de SP). Este corpus foi dividido em 6.171 unidades de contexto elementares (UCEs) e a análise considerou $73,81 \%$ do total de UCEs que o corpus possuía. A Figura 1 apresenta as classes de segmentos de textos obtidas pela classificação hierárquica descendente.

Conforme a Figura 1, a análise hierárquica descendente dividiu o conjunto de conteúdos dos artigos em 7 classes. Lendo o dendograma da direita para a esquerda, observa-se a divisão do corpus em dois subcorpus. O primeiro corresponde a $57,94 \%$ do total de UCEs selecionadas e abrange as classes: A soja no vaivém das commodities, Divulgação cientifica e ciência, tecnologia e sociedade-C,T\&S. O segundo subcorpus corresponde a $42,07 \%$ do total de UCEs selecionadas e contém as classes: A batalha judicial, A polêmica das medidas provisórias, Lei de Biossegurança e Fórum Social Mundial / Movimento dos trabalhadores rurais sem terra - FSM/MST. A Figura 1 também apresenta o número de UCEs que compõem as classes, indicando a porcentagem em relação ao número total de UCEs selecionadas, além dos anos e os jornais mais característicos de cada classe.

Cada classe foi nomeada de acordo com seu conteúdo específico. Geralmente, a delimitação do vocabulário mais significativo de cada classe é feita a partir de 2 critérios: (1) freqüência de ocorrência das palavras (freqüência superior à freqüência média das ocorrências por palavras no corpus = 26); e (2) prova de associação do qui-quadrado em relação à classe $\left(\chi^{2} \geq 3,84\right)$. Como o volume de artigos (e palavras) que compunham o corpus era muito grande e esses dois critérios não delimitavam um número pequeno de palavras, optou-se então por um terceiro: que mais de $50 \%$ das ocorrências da palavra tenham sido naquela determinada classe ${ }^{1}$. 


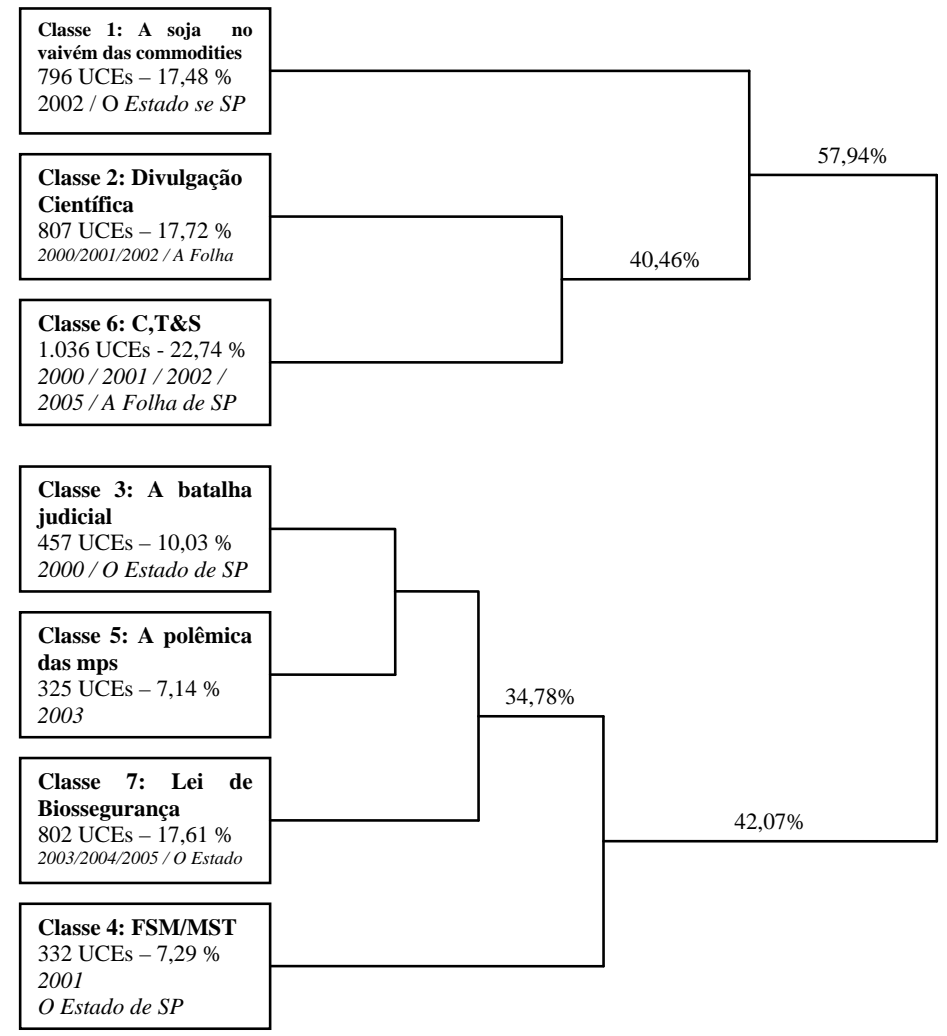

Figura 1. Classificação hierárquica descendente do conteúdo dos artigos sobre transgênicos publicados pelos jornais

A classe A soja no vaivém das commodities trata da importância que a soja adquiriu no mercado internacional e, principalmente da sua importância para o mercado e a economia nacional, sendo tratada como a "principal commodity brasileira". São apresentados argumentos contra e a favor da utilização dessa nova tecnologia na agricultura. Porém, esses argumentos não levam em consideração aspectos como os riscos para a saúde dos consumidores, o meio ambiente ou ainda as possíveis conseqüências sociais, considerando apenas os ganhos ou perdas econômicas que a adoção ou não dos transgênicos pode trazer para os produtores e para o país.

A classe Divulgação científica apresenta resultados de pesquisas sobre transgênicos publicadas em revistas científicas, principalmente no cenário internacional, caracterizando-se pela divulgação científica dos mesmos. O conteúdo dessa classe abrange três aspectos: (1) a divulgação científica, de forma geral, sobre transgênicos; (2) a aplicação da técnica da transgenia na medicina; e (3) na agricultura.

Nota-se o emprego de uma linguagem que tenta se aproximar à linguagem do cidadão comum. São utilizadas expressões para chamar a atenção, mas que também podem criar uma imagem de mostruosidade dos transgênicos. Além disso, a menção aos transgênicos para tratar de outros assuntos da biotecnologia moderna acaba levando à divulgação de informações erradas ou que podem confundir o leitor. A atividade científica em si também é discutida, em específico a motivação por trás das pesquisas, sendo feita uma reflexão sobre os interesses políticos e econômicos que se encontram por trás do desenvolvimento da pesquisa científica.

Na discussão sobre a aplicação da transgenia na área médica, os artigos empregam uma conotação predominantemente positiva, destacando os "importantes passos para o avanço científico". Não são apresentados os possíveis riscos que essa tecnologia pode trazer (nem mesmo para a saúde), e tampouco são discutidos os aspectos éticos e morais da aplicação dessa tecnologia. Na discussão da aplicação dos transgênicos na agricultura, uma grande parte dos artigos referente a esse aspecto também se posiciona favoravelmente à aplicação dessa tecnologia. Novamente são destacados os grandes "avanços científicos" feitos para melhorar a qualidade de vida dos homens. Porém, alguns destes artigos discutem os possíveis riscos dessa nova tecnologia, principalmente para a saúde humana e para o meio ambiente.

A classe $C, T \& S$ se relaciona diretamente com a classe Divulgação científica. Porém, se na classe anterior, a discussão sobre C\&T se restringia apenas aos transgênicos, na classe $C, T \& S$, essa lógica se inverte e os transgênicos são agora tomados como um exemplo, entre outros, para uma discussão maior sobre a relação entre ciência, tecnologia e sociedade. São consideradas as conseqüências, sociais e econômicas, que o desenvolvimento e aplicação da C\&T podem trazer. No entanto, são poucos os artigos dessa classe que propõem uma 
revisão da forma como o desenvolvimento da C\&T é conduzido atualmente ou uma reflexividade acerca das consequências sociais trazidas por tal desenvolvimento. A grande maioria dos artigos dessa classe ainda assume uma postura de apoio cego ao desenvolvimento científico-tecnológico, retratando-o como sinônimo de progresso. Alguns artigos argumentam que o investimento nesse desenvolvimento seria, justamente, a solução para acabar com a exclusão social de um país (principalmente o Brasil) e para se atingir a modernidade. O desenvolvimento tecnológico é um "desafio" que deve ser enfrentado pelos governantes do país, sem considerar a participação da população nesse processo.

A classe A batalha judicial relata o desenrolar dos julgamentos de uma série de ações na justiça, em relação aos transgênicos, que se iniciaram em 1998. A classe mostra que a legislação de 1995 referente aos transgênicos era confusa e deu oportunidade aos grupos de oposição (principalmente o Idec e o Greenpeace) para contestar o poder e a decisão da Comissão Técnica Nacional de Biossegurança (CTNBio) de liberar a soja transgênica da empresa Monsanto, baseados na preocupação com a segurança da saúde do consumidor e do meio ambiente. As divergências dentro da própria justiça brasileira e também do governo em relação à introdução dessa tecnologia no Brasil também são apresentadas. Porém, a discussão mais importante trazida pelo conteúdo dessa classe diz respeito à co-existência de diferentes leis dentro do sistema legislativo brasileiro que contribuíram para dar respaldo às diferentes decisões judiciais, alimentando o conflito entre os poderes legislativo e judiciário.

A classe A polêmica das medidas provisórias se relaciona diretamente com a classe anterior. $O$ que as diferencia é o fato de que, se o foco de discussão da classe A batalha judicial era a liberação da soja transgênica pelo sistema judiciário, essa classe explora a liberação da soja geneticamente modificada através do sistema legislativo. O conteúdo dessa classe faz referência à medida provisória 131, editada em setembro de 2003, que liberou o plantio e o comércio de soja transgênica para a safra de 2003/2004.

São discutidos os problemas decorrentes de um artigo dessa medida, o qual obrigava os produtores que pretendiam plantar soja transgênica a assinarem um Termo de Compromisso, Responsabilidade e Ajustamento de Conduta (TAC). De acordo com a MP 131, sem a assinatura do TAC, o produtor de soja transgênica não poderia fazer empréstimos oficiais, poderia ter a safra destruída, além de pagar multas. Alguns artigos dessa classe exploram a preocupação do produtor brasileiro em assinar esse termo e a pressão dos mesmos para modificá-lo no Congresso, quando a medida-provisória seria votada para ser transformada em Lei. Esses artigos retratavam o clima de insegurança causado pelo conflito entre os poderes legislativo e judiciário explorado na classe anterior. $\mathrm{O}$ medo dos produtores era de que a medida provisória fosse anulada pela justiça e eles tivessem que pagar pela infração cometida e confessada.

Essa classe também levanta uma discussão importante: a do papel da mídia na difusão de informações relativas ao processo de regulamentação e liberação dos transgênicos para a população e, em específico, para os produtores brasileiros. Alguns artigos dessa classe utilizavam títulos como "A soja transgênica está liberada no Brasil", para chamar atenção do leitor, mesmo quando a liberação era resultado de uma decisão de uma ação judicial - que ainda poderia ser contestada por recurso, portanto não definitiva - ou como resultado da edição de uma medida provisória - que liberava o plantio e comercialização por um ano, mas não definitivamente. A divulgação de artigos que não explicassem as implicações dessas decisões poderia levar o leitor a acreditar que o plantio de transgênicos estava legalmente liberado nessa época.

A classe Lei de Biossegurança se relaciona com as duas classes anteriores. Nessa classe, a discussão gira em torno da construção, no governo Lula, de um novo marco regulatório que definisse, clara e definitivamente, as regras que regem os transgênicos no país. Os anos significativamente associados a essa classe incluem o período em que o governo editou três medidas provisórias que liberavam, ainda que não definitivamente, o plantio e a comercialização da soja transgênica; apresentou o projeto da nova de Lei de Biossegurança; a tramitação do projeto e a aprovação da nova Lei no Congresso. Assim, o conteúdo dessa classe retrata o esforço do governo em liberar o plantio e a comercialização da soja transgênica no Brasil, discutindo as negociações dentro do governo para a criação da nova Lei de Biossegurança. Entretanto, a discussão mais importante feita por essa classe diz respeito à divergência em relação aos transgênicos dentro do próprio governo (principalmente entre o ministro da agricultura - que se posicionava publicamente a favor da rápida introdução dessa nova tecnologia no país - e a ministra do meio ambiente - que defendia o princípio de precaução), assim como aos conflitos entre os poderes executivo e legislativo no processo de regulamentação dos transgênicos no país. O conteúdo dessa classe retratou a aprovação da nova Lei de Biossegurança como uma derrota para os ambientalistas, e por outro lado, como uma vitória para o desenvolvimento científico-tecnológicoeconômico do país, assim como uma esperança para a cura de várias doenças.

A classe FSM/MST, apesar de estar relacionada às três classes anteriores, é a classe que mais se opõe ao conteúdo desse segundo subcopus. Apesar das classes $A$ batalha judicial e $A$ polêmica das MPs apresentarem a participação de atores que, tradicionalmente, não são considerados como parte da esfera política (Idec, Greenpeace e agricultores), a participação destes ainda se deu através de um sistema oficial: o judiciário. A classe Lei de Biossegurança retratou o processo de regulamentação dentro dos sistemas executivo e legislativo. Portanto, o que opõe a classe FSM/MST às demais, não é tanto a discussão da participação de atores não convencionais (nesse caso o MST), mas, principalmente, a discussão sobre o processo de regulamentação em um fórum alternativo, como o FSM, fora do que é tradicionalmente considerado como um lugar oficial de formulação de política.

O conteúdo dessa classe discute o MST e o FSM (e outros fóruns alternativos). Os transgênicos aparecem como um dos temas discutidos por esse grupo ou dentro desses fóruns. A discussão acerca dos mesmos leva a um debate maior sobre os rumos e alternativas para os modelos de agricultura e de desenvolvimento científico-tecnológico-econômico e social dos 
diferentes países e do mundo. São apresentados os argumentos, reivindicações e manifestações desse grupo, em parceria com outros movimentos nacionais e internacionais.

O conteúdo dessa classe mostra que a estratégia de protestos do MST em relação aos transgênicos envolvia ocupações, queima de sementes e destruição de plantios transgênicos. Porém, o grupo também pretendia empregar uma estratégia de comunicação para a população, seguindo a tática adotada pelos movimentos de outros países, como a distribuição de panfletos nos supermercados. Os argumentos empregados pelo grupo seriam que os transgênicos são prejudiciais à saúde, ameaçam o patrimônio da humanidade e levam ao fim do pequeno agricultor. Porém, os artigos desta classe destacaram somente as marchas e invasões feitas pelos grupos, sem comentar a estratégia de comunicação para a sociedade. Um dos diretores do movimento argumentou que os atos de protestos serviam para chamar atenção da sociedade e colocar a questão dos transgênicos em discussão. As próprias ações do MST são consideradas como a tática de contato do grupo com a sociedade. Em vez de adotar uma estratégia de comunicação, os atos de protestos servem para chamar atenção, passar uma imagem negativa dos transgênicos para a população e iniciar uma discussão sobre os mesmos.

A reação de algumas autoridades aos protestos organizados pelo grupo, também foi comentada nessa classe. O MST foi retratado como um movimento subversivo, e suas manifestações classificadas como "terroristas" e "que atentam contra a lei e a ordem, no estado e no país". Esse movimento também era representado como autoritário, ideológico, fanático e representa uma ameaça ao direito de propriedade dos cidadãos e à democracia do país. O FSM também foi caracterizado por alguns artigos como um movimento retrógrado e anti-democrático.

\section{Discussão}

A análise dos artigos mostrou que o conteúdo divulgado sobre transgênicos pelos jornais foi dividido em duas partes: uma caracterizada pela discussão acerca da introdução dos transgênicos no Brasil e outra parte caracterizada pela discussão acerca do processo de regulamentação dos transgênicos no país.

A discussão sobre a possível introdução dos transgênicos no país recebeu uma atenção maior dos jornais. Esse tipo de discussão considerou os aspectos econômicos, sanitários, ambientais e sociais que a introdução dessa tecnologia poderia trazer para o país. Tal discussão foi feita no período em que os transgênicos ainda estavam legalmente proibidos no Brasil.

A questão da introdução dos transgênicos no campo da agricultura, baseada somente em argumentos econômicos, teve um espaço considerável nos jornais. Isso confirma o argumento de Paarlberg (2002) de que as razões econômicas são fundamentais para se entender a adoção ou não dessa tecnologia pelos países em desenvolvimento. Isso também mostra que uma boa parte da discussão em torno da introdução dos transgênicos no Brasil ainda se encaixava dentro da lógica da sociedade de risco residual (Beck, 1999). Nessa decisão pesam apenas os ganhos econômicos. Mesmo quando eram apresentados os riscos, estes se referiam aos possíveis danos econômicos que essa decisão pode trazer. A lógica adotada nesse debate foi a de que "o mercado dita as regras". Assim, é o mercado que vai definir a introdução ou não dessa tecnologia e o tamanho da área plantada com transgênicos.

Alguns artigos apresentavam os benefícios dessa tecnologia para os produtores e para a economia do país. Outros artigos apresentavam os riscos (rebatendo os argumentos apresentados pelos outros artigos). Outros artigos ainda traziam ambos os argumentos, sem apresentar uma conclusão. Muitos artigos faziam um apelo à autoridade do especialista (analistas de mercado), sendo apenas um simples agente de ligação das opiniões das autoridades com às do público. Assim, pode-se dizer que foram empregados dois sistemas de comunicação pelos artigos correspondentes a esse tipo de discussão. Alguns artigos utilizaram a propaganda. Nesse caso, tanto os artigos que defendiam, quanto os que eram contra a introdução dessa tecnologia, visavam à formação de uma conduta específica (a utilização ou não dos transgênicos) por um grupo estruturado e orientado (o leitor / produtor). Outros artigos utilizaram o sistema da difusão, sem manifestar intenções bem definidas, nem manter uma orientação clara em relação à adoção dessa tecnologia, deixando as conclusões para o próprio leitor.

No que tange a discussão da aplicação dos transgênicos nos campos da saúde e da agricultura, dessa vez, considerando aspectos sanitários e ambientais, nota-se que tal discussão também teve um espaço considerável na mídia impressa brasileira. A lógica adotada nesse debate foi a do "avanço científico". Nesse sentido, os transgênicos eram frequentemente tomados como uma "revolução científica".

Quando essa aplicação foi considerada no campo da saúde, foram ressaltados apenas os benefícios que os transgênicos podem trazer, sem se discutir os possíveis riscos para a saúde e o meio ambiente, nem se tocar nos aspectos morais e éticos dessa tecnologia. Quando a aplicação foi considerada na agricultura, começaram a ser discutidos os riscos sanitários e ambientais. Mesmo assim, isso se referia a uma pequena parte dos artigos, a maior parte destes ainda se posicionava favoravelmente à aplicação dessa tecnologia nesse campo, destacando os grandes "avanços científicos" feitos para melhorar a qualidade de vida dos homens.

Esses resultados confirmam os resultados de outras pesquisas nacionais e internacionais. Bauer (2002) mostrou que a imprensa britânica "cultivou" uma representação da biotecnologia, contrastando a biotecnologia vermelha (aplicada ao campo da saúde) e a biotecnologia verde (aplicada à agricultura). Essa distinção regulou o debate público na Inglaterra, uma vez que focou na controvérsia da biotecnologia verde e resguardou a biotecnologia vermelha da atenção do público. No Brasil, Massarani, Magalhães e Moreira (2003) mostraram que a aplicação da biotecnologia na agricultura foi tratada de forma mais crítica pela mídia do que as demais aplicações.

Uma contribuição importante desse conteúdo diz respeito à possibilidade da análise da atividade de divulgação científica, mais especificamente do jornalismo científico. É notável que essa atividade, aqui, ainda se encaixa dentro da lógica de "déficit de conhecimento", na qual o medo ou a resistência do público frente a uma nova tecnologia são vistos como irracional ou 
sem fundamento. Assim, o papel dos divulgadores da ciência é esclarecer o público que é visto como homogêneo e ignorante. A divulgação científica exalta o "progresso científico". Pouco espaço foi dedicado para discussão dos riscos e interesses por trás do desenvolvimento da ciência. Esse resultado confirma o argumento de Bueno (2005) de que o jornalismo científico brasileiro tem desprezado as conexões entre ciência, tecnologia e poder.

Os artigos correspondentes a esse conteúdo também empregaram dois sistemas de comunicação. Pode-se pensar que os artigos que defendiam a aplicação dos transgênicos utilizaram a propagação. Nesse caso, esses artigos visavam não a formação de uma conduta, mas de uma atitude específica (a favor) por um grupo que pode estar dividido quanto à atitude em relação ao objeto social (os transgênicos). A utilização desse sistema de comunicação vai ao encontro do papel da divulgação científica dentro da proposta de fornecer mais informação para uma maior aceitação. O restante dos artigos utilizou o sistema da difusão.

O maior espaço dedicado pelos jornais em relação aos transgênicos corresponde a uma discussão maior sobre o papel da ciência e da tecnologia no desenvolvimento do país. A lógica dessa discussão foi a do progresso do país. Nesse sentido, o forte investimento no desenvolvimento (linear) da ciência e da tecnologia é a chave para o desenvolvimento (econômico) do país e do bem-estar da sua população. O investimento e a introdução dos transgênicos no Brasil segue essa lógica. São poucos os artigos que defendiam uma revisão da equação: mais $C \& T=$ mais desenvolvimento $=$ mais bem-estar, e propõem um exercício de reflexividade sobre os rumos do desenvolvimento científicotecnológico. Porém, a grande maioria dos artigos associados a esse conteúdo discutiu a relação entre ciência, tecnologia e sociedade ainda dentro da lógica da sociedade de risco residual na qual os riscos são percebidos como meros efeitos colaterais do processo de modernização e do progresso, são calculados, controlados e legislados por instituições de segurança, sem questionamento ou participação da sociedade (Beck, 1999). Nesse sentido, esse conteúdo retrata o medo e a resistência da população frente às inovações científicas como irracionais e sem fundamento. Ser contra a introdução dos transgênicos é ser contra o progresso do país. É preciso educar a população para que ela aceite e apóie esse desenvolvimento. Pode-se pensar que artigos associados a esse conteúdo também empregaram dois tipos de sistema de comunicação (a propagação e a difusão) dentro da mesma lógica da discussão anterior.

Como se pode ver, a discussão acerca da introdução dos transgênicos no Brasil, apesar de ter considerado os possíveis riscos (econômicos, sanitários, ambientais e sociais) que essa tecnologia pode trazer, enfatizou os benefícios da mesma. Tais benefícios foram considerados na área da saúde e, principalmente, no desenvolvimento econômico do país. Desse modo, pode-se dizer que esse debate representou os transgênicos, principalmente, como algo positivo para o indivíduo, a sociedade e o país.

A questão da regulamentação dos transgênicos no país recebeu uma atenção um pouco menor do que a questão da introdução, embora ainda considerável. O debate sobre o processo de regulamentação se caracterizou pela discussão feita em diferentes fóruns: oficiais (executivo, legislativo e judiciário) e alternativos (FSM); e por diferentes atores: convencionais (políticos, juízes, cientistas etc) e não convencionais (ONGs ambientais e de consumidores, MST etc).

A discussão acerca da polêmica gerada pelas medidas provisórias, apesar de muito pequena, abordou um aspecto muito importante: a pressão dos agricultores e do próprio governo federal para a introdução dos transgênicos no Brasil. A lógica adotada nesse debate também foi a de que o mercado dita as regras e os argumentos utilizados foram baseados apenas em aspectos econômicos. O sistema de comunicação predominantemente empregado pelos artigos correspondentes a esse conteúdo foi a difusão.

A discussão sobre o processo de regulamentação oficial da atual Lei de Biossegurança nacional mostrou para o público as negociações e as divergências dentro dos poderes executivo e legislativo durante o processo de regulamentação dos transgênicos no governo Lula. A lógica adotada nessa discussão também foi a do progresso do país, sendo priorizados os argumentos de que os transgênicos representam o desenvolvimento científico-tecnológico-econômico do país. Outra contribuição importante dessa discussão é que ela mostrou que o processo de regulamentação dos transgênicos no Brasil seguiu a lógica da formulação de política científica tradicional, ou seja, a portas fechadas, sem a preocupação de envolver o público e mesmo ignorando as manifestações de uma pequena parcela deste. O sistema de comunicação predominante entre os artigos correspondentes a esse conteúdo também foi a difusão.

A discussão sobre o papel da sociedade civil no questionamento da introdução dos transgênicos no Brasil, assim como no processo de regulamentação dos mesmos, teve um espaço restrito. Isso pode indicar duas coisas: que o espaço dedicado pelos jornais a essa questão foi pequeno, e que a própria participação da sociedade foi limitada.

Quando a participação da sociedade nessa questão se referia a organizações de consumidores (Idec) e ambientais (Greenpeace), a discussão foi feita em torno dos riscos para a saúde da população e para o meio ambiente. Outro questionamento importante feito por esses grupos diz respeito à autoridade e competência dos sistemas de controle da tecnologia (no caso a CTNBio). Assim, ainda que a participação desses grupos tenha sido pequena, esse conteúdo tocou em alguns pontos importantes, mostrou o início de uma reflexividade (ainda que por uma parte da sociedade) sobre os riscos residuais, de uma política direta e do questionamento dos sistemas de controle pela sociedade civil, apontados por Beck (1999). Além disso, esse conteúdo evidenciou a importância de um grupo propor uma representação social alternativa para se tornar ativo, para se fazer ouvir (Moscovici \& Marková, 2003). Entretanto, o sistema de comunicação predominante empregado pelos artigos correspondentes a esse conteúdo foi a difusão.

A discussão sobre o papel da sociedade civil também levou em conta a participação do MST, ligado a outros movimentos nacionais e internacionais. Nessa discussão específica, a contestação dessa tecnologia não foi mais feita em fóruns 
tradicionais. A participação se deu em fóruns alternativos (nas ruas e em fóruns mundiais). Além disso, são os riscos sociais e o modelo de desenvolvimento do país que foram questionados por esse grupo. Esse tipo de discussão continua a tocar em pontos importantes como: a organização da sociedade, a subpolítica e a proposta de um novo modelo de desenvolvimento. Também são debatidas as representações sociais alternativas e as estratégias de comunicação desse grupo para se tornar ativo. Porém, as alternativas propostas por esse grupo foram, muitas vezes, retratadas como um retrocesso. Assim, se o MST apresentava os transgênicos como algo negativo, esse grupo era representado negativamente por alguns artigos dessa classe e de outras também. Mais uma vez, o sistema de comunicação predominante nos artigos correspondentes a esse conteúdo foi a difusão.

Como se pode ver, a discussão acerca da regulamentação dos transgênicos no Brasil, apesar de apresentar uma discussão dos possíveis riscos dessa tecnologia, também enfatizou os benefícios da mesma, principalmente para o desenvolvimento econômico do país. Assim, essa discussão também representa os transgênicos de forma mais positiva. Apesar do debate sobre a participação da sociedade civil apresentar argumentos negativos, essa participação é representada, de forma geral, como um empecilho ao, ou retrocesso do desenvolvimento do país.

Tenta-se agora responder à questão de pesquisa: quais as representações sociais de transgênicos divulgadas pelos jornais brasileiros? Marková (2006) argumenta que, embora seja possível representar todas as coisas, nem todas as coisas são representações. Segundo a autora, as representações dizem respeito aos fenômenos sociais que se tornam alvo da preocupação pública, fenômenos que causam tensão. Moscovici (1978) também afirma que um objeto precisa se tornar alvo de interesse de um grupo para que este construa uma representação social deste objeto. Neste sentido, muitos argumentos, como a falta de uma reflexividade por grande parcela da sociedade brasileira, a lógica do desenvolvimento linear adotada pelo país, a falta de interesse por assuntos científicos-tecnológicos pela população, a tradição não-participativa de formulação de políticas, a ausência de um questionamento sobre assuntos como: segurança alimentar, modelo de desenvolvimento agrário etc., nos fizeram questionar se poderíamos falar de representações sociais de transgênicos no Brasil. No entanto, os resultados desse estudo nos levam a pensar que sim. Os resultados da análise descritiva mostraram que, pela quantidade de artigos publicados, os transgênicos, durante o período considerado, se tornaram no mínimo um assunto de interesse para o país, ainda que restrito a certos setores da população. Resta saber quais foram as representações construídas sobre os transgênicos e divulgadas pelos jornais.

Nascimento-Schulze e Camargo (2000) explicam que classes obtidas através da análise feita pelo programa ALCESTE podem indicar representações sociais ou, ao menos, campos de determinada representação. Os resultados da análise do conteúdo dos artigos mostraram que, de fato, cada classe abordou aspectos diferentes em relação aos transgênicos. Porém, argumentamos aqui que não se trata de diferentes representações sociais, mas de diferentes aspectos (ou campos) de uma mesma representação.
Cada classe tratava de um tema e a maioria delas apresentava duas linhas de argumento em relação a tal tema. Essas linhas de argumento se contradiziam e seguiam lógicas diferentes. Assim, é possível pensar que duas representações sociais de transgênicos foram divulgadas pelos jornais considerados.

Essas duas representações exemplificam o argumento de Moscovici (1978) de que no mundo moderno, marcado pela C\&T, as representações sociais sofrem suas influências e, desse modo, são constituídas em seu prolongamento ou em oposição a elas.

Pode-se supor que uma representação foi construída em oposição aos transgênicos. Aqui, os transgênicos se tornam um problema em relação à saúde do indivíduo, da família e da sociedade; um problema para o meio ambiente e para o mundo que será deixado para as gerações futuras; um problema para a sociedade que tem que lidar com questões como, desigualdade do acesso à tecnologia, desemprego, exclusão etc. Nessa representação, os transgênicos são tomados como um exemplo de $\operatorname{risco(s).~Cada~classe~abrange~um~aspecto~diferente~desse~}$ risco, mas que fazem parte da mesma representação. Nesse sentido, essa representação pode implicar uma posição crítica (Moscovici \& Marková, 2006), que estimula a crítica ativa na modernização reflexiva (Beck, Giddens, \& Lash, 1997). Especificamente, essa representação contribui para o processo de auto-reflexividade (como me posicionar frente aos transgênicos para garantir a minha segurança e a da minha família?), assim como para o processo de reflexividade estrutural (que tipo de desenvolvimento científico, tecnológico e econômico queremos para nosso país e para o mundo?). Entretanto, como se pôde ver pelos resultados da análise do conteúdo dos artigos, essa representação teve um espaço bastante reduzido nos jornais.

A outra representação foi construída no prolongamento da ciência e da tecnologia. Nesse caso, os transgênicos se tornaram um objeto de extremo interesse social. Tornaram-se também um problema, mas um problema de ordem diferente da apontada pela representação anterior. Tornaram-se um problema de ordem econômica. Mais que isso, um problema que pode se tornar uma solução. Nessa representação, os transgênicos são vistos como a solução para o desenvolvimento científico, tecnológico, econômico e social, uma solução para o progresso do país. Essa representação contribui para a manutenção do pensamento ligado à lógica da sociedade de risco residual, na qual os ganhos econômicos são priorizados em detrimentos dos possíveis riscos que a introdução de uma tecnologia possa trazer. Os resultados da análise dos artigos mostraram que essa representação teve uma presença predominante nos jornais.

De forma geral, as duas representações estiveram presentes em todos os anos considerados. Porém, nota-se que a discussão dos riscos dessa tecnologia feita no início do período considerado foi substituída nos anos seguintes pela discussão sobre os benefícios econômicos da mesma. Assim, a representação transgênicos como exemplo de risco(s) perdeu espaço para a representação transgênicos como progresso do país. Essa construção específica do discurso midiático sobre transgênicos pode ter tido implicações no processo de formação da opinião pública sobre os mesmos. 


\section{Considerações finais}

Essa pesquisa mostrou que a construção do discurso social sobre os transgênicos e, pode-se dizer que mesmo em relação ao desenvolvimento científico e tecnológico, contemplou inicialmente uma pequena discussão sobre seus possíveis riscos, mas foi sendo constituído em direção dos benefícios econômicos que tal desenvolvimento pode trazer.

Muitos dos teóricos apresentados nesse trabalho falam sobre a importância da informação, seja na construção das representações sociais, seja na ativação de uma reflexividade da sociedade. Nesse sentido, esses resultados levam a uma reflexão sobre o papel da mídia brasileira na construção da opinião pública a respeito dos rumos do desenvolvimento do país. Podese pensar que a mídia nacional ainda contribui mais para uma legitimação do modelo da sociedade de risco residual do que para a construção de representações sociais que possam ser usadas como armas críticas e que levem a um processo de reflexividade da sociedade sobre o melhor modelo de desenvolvimento e suas conseqüências para as gerações futuras.

Os resultados dessa pesquisa também mostram que o Brasil ainda está longe, em todos os sentidos, de alcançar as condições necessárias para uma reflexividade sobre os riscos do modelo de desenvolvimento linear adotado pelo país. A importância dada à comunicação e à informação vem junto com uma reflexão sobre a exclusão da sociedade ao acesso das mesmas. Nesse sentido, não é só o conteúdo divulgado sobre transgênicos, mas a própria exclusão do acesso a tal conteúdo que também contribui para uma não reflexão de grande parcela da população brasileira.

\section{Referências}

Auler, D., \& Bazzo, W. (2001). Reflexões para a implementação do movimento CTS no contexto educacional brasileiro. Ciência e Educação, 7(1), 1-13.

Bauer, M. (1994). A popularização da ciência como imunização cultural: a função de resistência das representações sociais. In P. A. Guareschi \& S. Jovchelovitch (Orgs.), Textos em representações sociais (pp. 229-257). Petrópolis: Vozes.

Bauer, M. (2002). Controversial medical and agri-food biotechnology: a cultivation analysis. Public Understanding of Science, 11, 93-111.

Beck, U. (1997). A reinvenção da política: rumo a uma teoria da modernização reflexiva. In U. Beck, A. Giddens, \& S. Lash (Orgs.), Modernização reflexiva: política, tradição e estética na ordem social moderna. São Paulo: UNESP.

Beck, U. (1999). World risk society. Cambridge: Polity Press.

Beck, U., Giddens, A., \& Lash, S. (1997). Modernização reflexiva: política, tradição e estética na ordem social moderna. São Paulo: UNESP.

Bonfadelli, H., Dahinden, U., \& Leonarz (2002). Biotechnology in Switzerland: high on the public agenda, but only moderate support. Public Understanding of Science, 11, 113-130.

Bueno, W. (1999). As sementes da discórdia: A questão dos transgênicos em seis jornais brasileiros. Obtido de http://www.agricoma.com.br.

Bueno, W. (2005). Decifrando o DNA do jornalismo cientifico. Obtido em 20 de maio de 2005, de http://www.comunicacaoempresarial.com.br.

Camargo, B. (2005). ALCESTE: Um programa informático de análise quantitativa de dados textuais. In A. Moreira, B. Camargo, J. Jesuíno \& S. Nóbrega (Orgs.), Perspectivas teórico-metodológicas em representações sociais. João Pessoa: Editora da Universidade Federal da Paraíba.

Einsiedel, E., \& Kamara, M. (2006). The coming of age of public participation.
In G. Gaskel \& M. Bauer (Orgs.), Genomics and society: legal, ethical and social dimensions (pp. 95-112). Londres: Earthscan.

Fischler, C. (2000). Quand les crises alimentaires réveillent les utopies. Biotechnologies: Fascinations... Interpellation \& Etre de son Temps à la Champagne. Obtido em 18 de maio de 2006, de http://www.agrobiosciences. org.

Frewer, L., Miles, S., \& Marsh, R. (2002). The media and genetically modified foods: evidence in support of social amplification of risk. Risk Analysis, 22(4), 701-711.

Giddens, A. (2002). Modernidade e identidade. Rio de Janeiro: Jorge Zahar.

Görke, A., \& Ruhrmann, G. (2003). Public communication between facts and fictions: on the construction of genetic risk. Public Understanding of Science, 12, 229-241.

Guivant, J. (2001). A teoria da sociedade de risco de Ulrich Beck: entre o diagnóstico e a profecia. Estudos Sociedade e Agricultura, 16, 95-112.

Guivant, J. (2002). Heterogeneous and unconventional coalitions around global food risks: integrating Brazil into the debates. Journal of Environmental Policy \& Planning, 4, 231-245.

Guivant, J. (2005). A governança dos riscos e os desafios para a redefinição da arena pública no Brasil. In E. Silva, M. Santos, \& P. Bacarense (Orgs.), Ciência, Tecnologia e Sociedade: novos modelos de governança (pp. 4785). Brasília: CGEE.

Gutteling, J. et al. (2002). Media coverage 1973-1996: trends and dinamics. In M. Bauer \& G. Gaskel (Orgs.), Biotechnology: the making of a global controversy (pp. 95-128) Cambridge: Cambridge University Press.

Jodelet, D. (1986). La reprsentación social: fenómenos, concepto e teoría. In S. Moscovici (Org.), Psicología social II. Barcelona: Paidós.

Jodelet, D. (2001). Representações sociais: um domínio em expansão. In D Jodelet (Org.), As representações sociais (pp. 17-44). Rio de Janeiro: Editora da Universidade Estadual do Rio de Janeiro.

Labarrère, M. (2000). A atual legislação de biossegurança no Brasil. Cidadania e Justiça, 4(9), 202-219.

Lazzarini, M. (2000). Alimentos transgênicos: a precária avaliação dos riscos à saúde. Cidadania e Justiça, 4(9), 195-201.

Marcolino, E., \& Franco, F. (2004). Transgênicos: a falta de informação pode intoxicar o leitor. Comunicação e Saúde, 1(1), s/p.

Marková, I. (2006). Dialogicidade e representações sociais: as dinâmicas da mente. Petrópolis: Vozes.

Massarani, L., Magalhães, I., \& Moreira, I. (2003). Quando a ciência vira notícia: um mapeamento da genética nos jornais diários. Ciência \& Ambiente, 26, 141-148.

Moscovici, S. (1961). La psychanalyse, son image et son public. Paris: Presses Universitaires de France.

Moscovici, S. (1978). A representação social da psicanálise. Rio de Janeiro: Zahar.

Moscovici, S. (2000). The phenomenon of social representations. In S. Moscovici \& G. Duveen (Orgs.), Social representations: Explorations in social psychology (pp.18-77). Cambridge: Polity.

Moscovici, S., \& Marková, I. (2003). Idéias e seu desenvolvimento - um diálogo entre Serge Moscovici e Ivana Marková. In S. Moscovici (Org.), Representações sociais: investigações em psicologia social (pp. 305-387). Petrópolis: Vozes.

Nascimento-Schulze, C. M., \& Camargo, B. V. (2000). Psicologia social, representações sociais e métodos. Temas em Psicologia da SBP, 8(3), 287-299.

Paarlberg, R. (2002). The real threat to GM crops in poor countries: consumer and policy resistance to GM foods in rich countries. Food Policy, 27, $247-250$.

Parales-Quenza, C. J. (2004). Preferences need no inferences, once again: germinal 
elements in the public perceptions of genetically modified foods in Colombia. Public Understanding of Science, 13, 131-153.

Porto, M. (2005). Riscos, incertezas e vulnerabilidades: transgênicos e os desafios para a ciência e a governança. Política \& Sociedade, 7, 77-103.

Reinert, M. (1998). Alceste: Analyse de données textuelles. Manuel d'utilisateur. Toulouse: IMAGE

1 Normalmente, o dendograma apresentado contém tabelas que apresentam as palavras associadas a cada classe, sua freqüência e seu valor de qui-quadrado. Porém, mesmo com os três critérios utilizados para definir o vocabulário específico, as classes apresentavam muitas palavras associadas (em média, mais de 50), tornando impossível, por causa do espaço, apresentar tais tabelas.

Juliana Mezzomo Allain, doutora em Psicologia pela Universidade Federal de Santa Catarina, é aluna de pós-doutorado em Sociologia pelo Núcleo Interdisciplinar em Sustentabilidade e Redes de Agroalimentares (NISRA), da mesma universidade. Endereço para correspondência: Avenida Engenheiro Mesquita, 715/503 (Centro); Araranguá, SC; CEP: 88900-000. Telefone: (48) 3521-0457. E-mail: jumezzomo@hotmail.com Clélia Maria Nascimento-Schulze, PhD em Psicologia Social pela Bristol University, é professora titular aposentada da Universidade Federal de Santa Catarina. E-mail: cleli@matrix.com.br

Brígido Vizeu Camargo, doutor em Psicologia Social pela École des Hautes Études en Sciences Sociales, é professor associado da Universidade Federal de Santa Catarina. E-mail: brigido.camargo@yahoo.com.br 